\title{
THE RE-INTRODUCTION OF ARITHMETIC INTO THE HIGH SCHOOL COURSE.*
}

Bx Harrison E. WebB,

Central Commercial and Manual Training High School, Nerwark, N.J.

The mathematical curriculum of a manual training high school is one of the most difficult of the problems which this type of school has to face. The traditional high school course has been tried and found wanting for various reasons, some of which may well be enumerated here.

The first of these reasons is identical with the fundamental question as to whether the orthodox canon of high school mathemathics has ever justified its existence from any point of view. The canonical sequence of algebra, plane and solid geometry, and plane trigonometry seems to have been imposed upon American high schools by the colleges, as the colleges themselves came to need more and more time for the physical sciences and history. Fifty years ago many students entered our colleges from the grammar schools through the intermediary of a year or two of private tuition. This tuition, as well as the grammar school teaching, was largely informative in character in that it led directly to an entrance examination, which was to test whether the amount of information which the student had acquired was sufficient to enable him to proceed further in his studies. The preparatory work in mathematics was scarcely less informative, in this senise of the word, than that in Latin and Greek.

Once inside the sacred portals of the college, however, the student was confronted by quite a different situation. Here his studies had an aim which was distinctly disciplinary. It was safe to assume that one who had "brains" enough to master the amount of Latin, Greek, mathematics and metaphysics required for graduation from a college would succeed as a lawyer, or a doctor, or a clergyman, or in any thing else he might undertake. It was assumed that his life work commenced at "commencement". and not before, and that his college had inspired in him the habit of success.

The immense broadening of the field of human knowledge during the past fifty years, roughly speaking, has brought about a curious interchange of purposes of high school and college.

*Read before the Association of Mathematics Teachers of the Middle States and Maryland, heid at Philadelphia, Nov. 24, 1912. 
During this period the colleges rapidly enlarged the scope of their instruction. Scientific courses expanded and multiplied enormously. English literature was raised to the dignity of university consideration. History was given a place worthy of its high importance in liberal education. Professional and graduate schools in law, medicine, engineering, and theology appeared in great numbers, and college education in the broad sense of term, became distinctly informative in character along definite lines which should lead directly to professional work.

Meanwhile the secondary school acquired a distinct status as the proper intermediary between the grammar school and the college, and its work gradually took on a disciplinary character. The idea of secondary education as primarily a discipline was encouraged by the colleges as it came to be recognized that a mind properly trained through four years of high school work can later acquire a great deal of information on very short notice.

This change in the aim and purpose of the high school, however, was accompanied by another change in a widely different direction. Secondary schools throughout the country were transferred from private to public supervision and became an integral part of our admirable public school system. An enormous increase in attendance was the result, and as a further result the burden of selecting proper material for the colleges was placed upon the high school authorities. It soon appeared that by far the larger proportion of high school students, for economic or other reasons, were not to enter college at all, nor even, perhaps, to "graduate" from the high school itself.

The problem of reconciling a proper degree of discipline with the imparting of a reasonable amount of information in a high school course is only in process of solution. It would be a very rash performance to predict the outcome. What part is mathematics to play in solving the problem? The remarkable thing about this phase of the question is that amid all the changes in secondary school curricula-the gradual disappearance of Greek, increased emphasis upon English, improved methods of teaching modern languages, and other improvements too numer.ous to mention, high school mathematics has stood stock still. I suppose that this statement should be qualified by reference to the addition of a certain few topics, and the elimination of two, highest common factor by the Euclidean method, and the socalled theory of limits in geometry. Even this awe-inspiring transformation has taken place only within the last decade. 
Why this conservatism? Why has it taken longer, as some one has said, to eliminate the absurdities of the "theory of limits" from geometry than it took for Alexander to conquer the world, or for Luther to reform the religion of half of Germany?

The chief reason, I think, lies in the necessity placed upon teachers of judging pupils as well as instructing them. And judgments such as we must make, among students whose aims range all the way from entrance into the most exacting technical schools to the killing of time until somebody in authority sets his foot down, such judgments seem to demand great precision in the determination of proper standards. The result is that our mathematical curriculum has become standardized to an extent which is almost inhuman. We have set the orthodoxy of our topical analysis above the welfare of the student. We have even set it above the spirit of the mathematics. Our teaching has taken on more and more the character of an inquisition. A teacher of high school mathematics of ten years' experience not only knows every twist and turn of the subjects he teaches, but he can generally foresee just what mistakes are going to be made in his classroom, and what students are going to make them. And he concludes his year's work with examinations, the results of which he can foretell to a nicety, so rigid is our adherence to the classical forms of our abstract material.

And yet it is a fact that the curriculum itself is largely accidental. The logic of the situation is decidedly vague, to say the least. There is no logical reason why our preparatory mathematics "should not now be in the field of substitution groups or of elementary vector analysis, if the Arabs or the Greeks had happened to think of them!"

The alteration of our standards is no easy task, however, even with the encouragement of the very liberal spirit recently shown by the colleges in this regard. Imagine trying to introduce into a high school such mathematical courses as were above mentioned! I would not be so bold at this time as even to recommend any very radical changes. But first of all we must pull down otr fetich; we must lose entirely our present high regard for mere intricacy. We must appreciate that neither scholastic ability in general, nor mathematical ability in particular, is to be measured in terms of the negative exponent, or of the geometrical locus. But we can afford to be careful in making improvements. We are not álone in our efforts toward reform. Religious heterodoxy is in the air. Professor Bergson is treating our metaphy- 
sicians to a series of moral cold baths. Eminent statesmen are thundering against the intricacies of the law. Standards of morality are concealing themselves behind the "higher good." Let us by all means be careful.

Let us be careful in considering the argument from discipline. Within the last decade we have heard much of the "real problem," and its importance to vocational courses of study. But can we safely assert that we are able to reproduce in our schools such real conditions as the student must meet in his work outside? To just the extent to which we fail to do this our high school studies are essentially disciplinary. It is doubtful if, having assumed the responsibility of judging the absolute merit of our students, we can ever escape from disciplinary methods. The question is whether under existing conditions the discipline is of the right sort. Most of us will agree, I think, that it is not. If it were, we would not have to listen to the indignant protests of the teachers of physics that they are obliged to spend more time in instruction in mathematics than in what they regard as their own proper field. If it were, we would not have presented to us constantly the spectacle of the student who can disentangle the most elaborate complex fractions, and yet who cannot solve the simplest examples in chemistry under the law of contsant proportions. If it were, we would not "pass" students who can solve simultaneous quadratic equations of the fourth degree with the greatest of ease and yet who cannot determine the horse power of a steam engine when the formula and the necessary data are given them in the plainest of terms.

What are we doing? What sort of mathematical fare are we providing for our charges? Take the average first year course, for example. What do we find? Forty-seven varieties of factoring, all by guess work, and all of which we curse deeply, if not aloud, when we come to quadratic equations; algebraic fractions which reach across the page of the textbook; simultaneous equations in innumerable variables, which appear again only as a proper field for the application of determinants, which we do not teach, or in geometry of three or more dimensions, of which not more than one out of five hundred of our students ever hears; utterly impossible exponential relations; and finally problems! Inconceivable dogs chasing incomprehensible rabbits; railroad trains, the data regarding which no one but a lunatic would ever present to a train dispatcher; the time when the hands of a clock are at right angles- this problem has a factitious interest 
for our students in that it affords them an excuse for glancing at the clock face, which they are generally anxious enough to do. And so on, ad nauseam.

In the meanwhile, what are we failing to teach? Any notion whatever of the significance of approximate values of irrational or imperfectly determined numbers; the faintest glimmer of the function concept, which is perhaps the most important of all fundamental concepts of elementary mathematics; ratio and proportion in any adequate sense of their relation to physical law; and anything like a sure knowledge of the four fundamental oper. ations and the laws governing them.

And then when we reach the second year, we drop the whole body of algebraic knowledge which we have been so careful to inculcate and plunge our classes into a sea of Euclidean metaphysics as if algebra had never existed. Small wonder that the teachers of scientific branches have trouble with the students we send to them! Small wonder that so many of the students themselves look upon the mathematics as a stale and unprofitable thing! Small wonder that the colleges complain without ceasing of the hopelessly inadequate mathematical training of those we send to them!

And yet, absurd as the present situation is, we are wise in moving slowly toward its betterment. The mathematical curriculum, like the tariff, should be revised only by slow degrees. Most of us are painfully aware of the demoralization which has resulted from certain well-meant attempts at radical reform. There was the real-problem movement, for instance. Nothing should be in closer theoretical accord with the best pedagogics. And yet those of us who tried conscientiously to limit the scope of algebraic application to actual conditions arising out of the shops and laboratories were completely at a loss owing to the paucity of meterial. Many hours we spent in the search for quadratic equations only to be rewarded with $S=u_{0} t+1 / 2 g t^{2}$ standing in solitary grandeur.

What I have to propose is not so much a new curriculum as a renewed emphasis. The word which best conveys the meaning of what I would like to see emphasized is "application." This word has to my mind many connotations; first it involves the organic unity of our teaching, in that the importance of a principle or of an exercise lies in its bearing upon what is to follow, the more direct the more important. The future outlook of a science is its chief source of interest. We have, I believe, partly 
through the Greek tradition and partly through an erroneous psychology, laid altogether too much emphasis upon the derivative side of our science. If a student, for example, is forbidden to use his algebra freely in geometry, where can he expect to use it?

Second, the word "application" seems to me to involve all that is vital in the doctrine of correlation as applied to high school studies. Experiments along this line have led many of us to the conclusion that the proper place for correlation is in the mind of the student, rather than in the topical analysis of the curriculum. Why not take this point of view frankly? To cite an instance or two; it is one thing to insist that geometrical figures shall be drawn with all the care demanded in the drafting room; it is quite another thing to emphasize the geometrical principles underlying the use of the T-square, or the parallel ruler, or the construction of a spiral. It is one thing to teach the atomic theory of heat to a first year class in high school. It is quite another thing to insist throughout the elementary algebra upon the use of significant letters, and to devote considerable time to the evaluation of formulae like those for the linear and cubical expansion of solids under increased temperature, for fractional and decimal values of certain letters; and to transform these formulae by the solution for some one of the Jetters supposed to stand for an unknown quantity. A mere statement of the purposes of the formulae often arouses great interest among the students.

Now the branch of mathematics which is most distinctly applicative in character is the one which we generally neglect in high school, viz., arithmetic. It is not so many years ago that arithmetic had its place in the high school and was required for entrance to college. It was squeezed out by the pressure of other strbjects. I believe that we would have a better mathematical curriculum today if the arithmetic had been left in, and some of the Euclid dispensed with. But the learned Greek overawed us. I would propose, in short, the restoration of arithmetic to its rightful place in the first year of the high school course.

A manual training high school offers an excellent opportunity to attempt this, for several reasons, chief among which is the constant need for arithmetical skill in the shop work. It should be noted also that college preparation is distinctly of secondary importance in such a school, so that the algebraic exercises need not necessarily adhere to an artificial standard of intricacy. 
The Central Commercial and Manual Training High School of Newark, N. J., has undertaken to modify the traditional mathematical curriculum by devoting the first year to arithmetic, the second to algebra through logarithms, and the third to plane geometry. The arithmetic, however, is something more than a review of the work of the grammar school.

The course in commercial arithmetic does not differ essentially from that offered in most commercial schools, except in so far as placing it in the first year constitutes a difference. The course in technical arithmetic may be worth mentioning in detail. At the outset of the course there is presented the significance of negative numbers and of literal quantities. This is not so much for the purpose of algebraic analysis, as to make it possible for the student to summarize arithmetical principles by means of simple formulae and to appreciate the importance of arithmetical processes in the evaluation of such formulae.

The four fundamental processes of arithmetic are extended to include literal expressions, which are simple in form, and the laws of these processes are explained and exemplified. Numerical and literal examples are mingled indiscriminately here, and as well in the study of common fractions which follows. Only two cases of algebraic factoring are presented-the removal of the common monomial factor, and the perfect trinomial square, which is applied in arithmetical square root.

Ratio and proportion are emphasized, with applications to similar figures, to specific gravity, to the lever, the inclined plane, the pulley, and the screw, and to the chemical law of constant proportions. Literal as well as numerical examples are presented under this topic. Percentage and interest are reviewed, and their principles summarized in formulae. The metric system comes in for a large share of attention, with transformations to other United States standards.

A large measure of geometry (de-Euclidized) is presented under the alias of mensuration; and this is extended in the way of application to the principles of denominate numbers. The use of cross-section paper in illustrating mathematical relations is introduced at this time, and the effort is made to develop in the mind of the student some notion of the function concept.

Throughout the first year course emphasis is laid upon two points, first, the statement of the solution of a problem in symbolic form, and with it the generalization of the solution by the use of literal numbers; and second, the application to particular 
cases of general methods of solution. In a word, the aim is to acquaint the student with algebra as a generalized arithmetic, and with arithmetic and simple geometry as fields for the application of algebra. Ample time is reserved, however, for the consideration of specific problems which may arise in the shops.

As this course has been in operation less than two years, it is too early to report upon its influence upon the work in formal algebra and geometry. But my own faith in its beneficence is very strong. - The need for both algebra and geometry is brought out. very clearly in the first year, and their practical value is made so plain as to be unmistakable. The review of particular topics in arithmetic serves to gather up the loose ends of the mathematical work of the grammar schools. The fundamental principles of numbers are more distinctly defined than in the grammar school would be considered desirable. And as has been seen, the scope of the subject has been enlarged somewhat. This change I am sure is justifiable. There is no reason, for example, why a student should postpone his knowledge of the meaning of the term "horsepower" until he has mastered or memorized certain highly metaphysical ideas regarding the absolute unit of force. The computation of the horsepower of a steam engine, or of the horsepower required by a hydraulic pump is really nothing but arithmetic mingled with a little common sense.

I would go even farther in holding the opinion that the students entering college would be in much better mathematical trim if arithmetic were required for college entrance. I believe that arithmetic in the rightful place as a correlative of algebra and geometry would dispose effectually of many of the absurd formalisms for which high school teachers are now held responsible.

Finally, and not of the least importance, is the fact that the student who for economic or other reasons is able to spend but one year in high school may under the above arrangement acquire a body of information of considerable value, in place of the rattling bones of a dead science. 